\title{
An intravasal non-occlusive contraceptive device in rats
}

\author{
M. M. Misro, Harpreet Kaur, Sudha Mahajan and S. K. Guha \\ Centre for Biomedical Engineering, All India Institute of Medical Sciences and Indian Institute \\ of Technology, New Delhi - 110 029, India
}

\begin{abstract}
Summary. An implantable miniature biogalvanic cell was developed to kill the spermatozoa in the vas deferens by an electric current. Experiments in vitro and in vivo showed that a combination of aluminium/silver electrodes connected with platinum wires with the vas deferens fluid as an electrolyte is effective in killing spermatozoa. Female rats paired with males having biogalvanic devices in the vas deferens, which remained patent, did not produce any young.
\end{abstract}

\section{Introduction}

There is continuing research on minimizing the problems of vasectomy; some workers aim to achieve better methods of occlusion (Brueschke et al., 1975; Guha, Ahmed \& Kaur, 1976) while an alternative approach is to maintain the patency of the excurrent ducts but to kill the spermatozoa. Ahsan, Farooq, Kapoor \& Laumas (1976) have reported that if a copper wire is placed in the lumen of the vas deferens the spermatozoa flowing past the wire are killed. Presumably the copper ions released by the wire are absorbed by the spermatozoa. This effect is operative only at the surface of the copper element and it is likely that large numbers of spermatozoa pass the wire and live. Moreover the emission of copper ions leads to rapid erosion of the wire. Spermatozoa can be destroyed by subjecting them to an electrical current field (Mahajan, Goel, Guha \& Misro, 1978; Mahajan, Guha \& Misro, 1980).

Since implantation of batteries is impracticable it is necessary to have a current-generating biogalvanic cell (Tarjan, 1973). The present paper considers the effect of a bimetal combination with the vas deferens fluid as electrolyte.

\section{Materials, Methods and Results}

\section{Selection of materials}

Material combinations which are far apart in the electrochemical series in principle can be used for biogalvanic cell formation. The actual potential differences obtained also depend on the electrolyte medium. While data with saline solution are available, there are no data for vas deferens fluid. A small cell was therefore prepared in which the metal electrodes could be kept 1 $\mathrm{mm}$ apart. Each electrode measured $1.5 \mathrm{~mm}$ in length and $0.05 \mathrm{~mm}$ in diameter and was connected to a voltage-measuring system shunted with a resistance of $1 \mathrm{kohm}$. The lead connections were of platinum wire. The resistance of $1 \mathrm{kohm}$ was incorporated to simulate the electrical loading effects that would be present in vivo.

Mature albino rats weighing $250 \mathrm{~g}$ were killed and immediately multiple punctures were made in the epididymis to allow the epididymal fluid to ooze out. This fluid was sucked into a Silastic (Dow-Corning, Michigan, U.S.A) tubing of lumen diameter $1 \mathrm{~mm}$ and transferred to the 
cell in between the metal electrodes. An initial high potential difference was always obtained and thereafter the potential declined and stabilized after about $5 \mathrm{~min}$.

The potential difference data for the different metal combinations were used to give the potential gradient equivalents shown in Table 1 and Text-fig. 1. Copper-silver, silver-aluminium and graphite-aluminium gave fairly high values of potential gradients. In some in-vivo tests copper-silver was used because of the convenience of joining lead wires both to copper as well as silver, but it was difficult to separate the contribution of copper ion release from the efficacy of the biogalvanic effect. For all further tests silver-aluminium electrodes were used in spite of the difficulties of connecting the platinum wires to aluminium.

Table 1. Potential gradients of different electrode pairs

\begin{tabular}{lcc}
\hline & \multicolumn{2}{c}{ Potential gradient (V/mm) } \\
\cline { 2 - 3 } Electrodes & $\begin{array}{c}\text { Maximum immediately after } \\
\text { closing the circuit }\end{array}$ & Stabilized \\
\hline Copper-silver & 0.60 & 0.16 \\
Copper-aluminium & 0.58 & 0.13 \\
Copper-graphite & 0.40 & - \\
Silver-aluminium & 0.70 & 0.33 \\
Silver-graphite & 0.05 & - \\
Graphite-aluminium & 0.60 & 0.17 \\
\hline
\end{tabular}

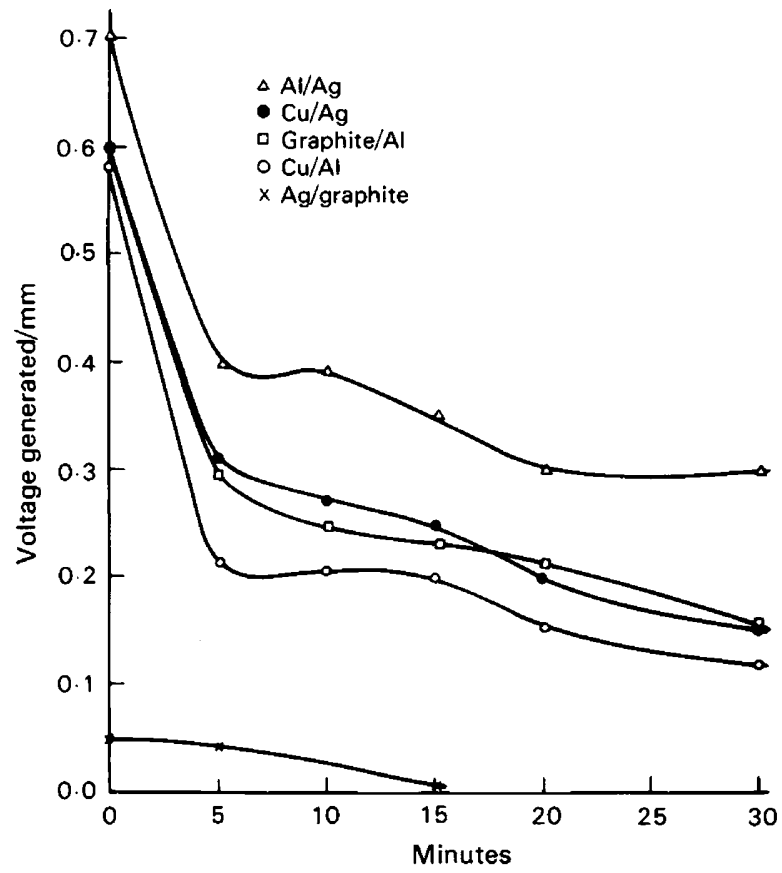

Text-fig. 1. Potential gradients with electrode pairs of different composition with respect to time.

In another set of experiments using the same cell, the specific resistance of spermatic fluid was measured with a $1 \mathrm{kHz}$ bridge and the value obtained was $110 \mathrm{ohm}-\mathrm{cm}$. 


\section{Biogalvanic effects in vitro}

These studies were performed using the same type of cell as described above except that the shunting $1 \mathrm{kohm}$ resistance was not used. Epididymal fluid was withdrawn and placed in the cell for periods of up to $25 \mathrm{~min}$. The fluid samples were then removed using Silastic tubing and examined microscopically for the percentages of spermatozoa surviving. In one experiment the fluid was placed in the cell but the platinum connecting wires were not connected, i.e. the biogalvanic potential was present but there was no current. As a further control the experiment was repeated with the fluid in a cell without any metal electrodes. The results are shown in Text-fig. 2. The survival of the spermatozoa for the cell with the electrodes in place but no electrical circuit was comparable to that when there were no metal electrodes. The spermatozoa died very rapidly when the electrodes were shorted.

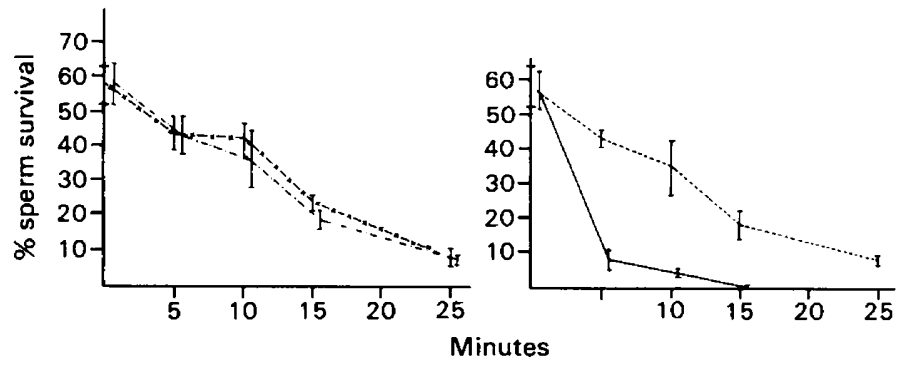

Text-fig. 2. Rat sperm survival rate in vitro without any electrodes $(x-x-x)$, with Teflon pieces only $(\cdot-\cdot-\cdot-\cdot)$, with aluminium-silver electrodes but the electrical circuit not complete $(----)$ and with aluminium-silver electrodes and a completed electrical circuit ( - ). Values are mean \pm s.e.m. for 10 tests at each time.

\section{Contraceptive effectiveness tests}

Mature albino rats (Wistar strain) of proven fertility and weighing about $200 \mathrm{~g}$, were allocated to 4 groups of 10 animals each.

The rats in Group I were unilaterally vasectomized and received no devices, in Group II Teflon (Aflon Engineers Ltd, Ahmedabad, India) devices without metal electrodes were implanted, in Group III devices with A1/Ag electrodes (Text-fig. 3) were implanted but the electrical circuit was not completed, in Group IV Teflon devices with $\mathrm{Al} / \mathrm{Ag}$ electrodes were implanted and the electrical circuit was completed.
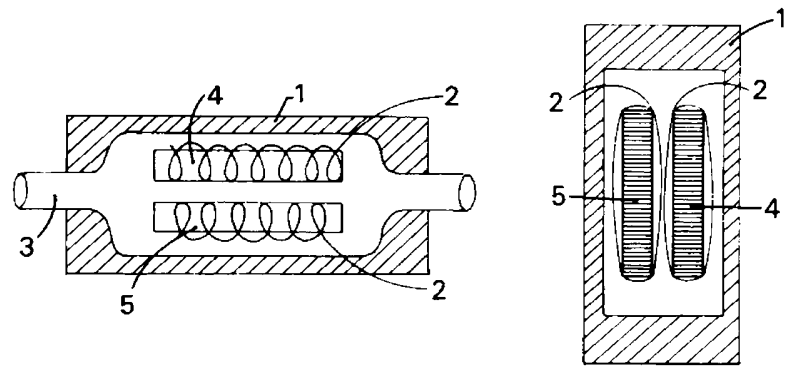

Text-fig. 3. Schematic diagram of the device showing the arrangement of electrodes. 1, Tefion outer case, $4.5 \mathrm{~mm}$ diameter, $0.8 \mathrm{~cm}$ long; 2 , platinum connecting wires joined to complete circuit; 3 , end tubes of $0.5 \mathrm{~mm}$ outer diameter; 4 and 5 , the electrodes of different metals.

In each rat the device was unilaterally implanted (ether anaesthesia) in the vas deferens while the other vas deferens was cut and ligated. The animals were maintained in normal husbandry conditions for 6 months. Each rat was placed with two pro-oestrous females 1 week after 
surgery. The fertility results are given in Table 2. Vaginal smears taken twice each week were immediately examined under the microscope.

Table 2. Fertility performance in male rats with various devices implanted in the vas deferens

\begin{tabular}{lccc}
\hline Group & $\begin{array}{c}\text { No. of males } \\
\text { tested }\end{array}$ & $\begin{array}{c}\text { No. of females } \\
\text { conceiving }\end{array}$ & \% fertility \\
\hline I & 10 & 20 & 100 \\
II & $10^{*}$ & 16 & 80 \\
III & $10^{*}$ & 16 & 80 \\
IV & 10 & 0 & 0 \\
\hline
\end{tabular}

* One male rat had a blocked device.

Except in one Group-II rat and another in Group III, live and dead spermatozoa were present in the smears, confirming the patency of the duct. Direct evidence of fertility was obtained by allowing the females to litter. Subsequently, the males were killed and the site of implantation of each device was examined to check whether the devices had been displaced and a vas deferens bypass of the device had occurred. In all animals the devices were in place. Further, the fluid in the distal vas deferens contained live as well as dead spermatozoa according to the nature of the device.

\section{Longevity of the device}

A true estimation of the longevity of the device can be obtained only from long-term trials. Nevertheless, the implantation tests indicated that even in 6 months most of the devices remained patent. Displacements of the device are most likely to occur within the first 3 weeks after implantation. Interelectrode current also stabilized very soon after implantation.

Therefore progressive erosion of the electrodes seems to be the only possible factor limiting the lifespan of the technique. To assess this variable studies were carried out with a group of 6 male rats of the same type as used in the earlier experiments. Electrically completed devices with $\mathrm{Al} / \mathrm{Ag}$ electrodes were implanted as before. Each electrode was weighed before implantation, the mean weights being $4.2 \pm 0.1 \mathrm{mg}$ silver and $4.0 \pm 0.15 \mathrm{mg}$ aluminium.

At 3 months after the implantation the devices were removed and the electrodes were weighed again after washing and drying. The values were $4.0 \pm 0.4 \mathrm{mg}$ silver and $3.1 \pm 0.13 \mathrm{mg}$ aluminium. Although there was a loss in weight, particularly of the aluminium electrodes, because the current density as well as the erosion rate immediately after implantation is high and then declines, it is reasonable to conclude that the device will have a lifespan of several years.

\section{Discussion}

These experiments clearly demonstrated that the metal electrodes themselves did not have a spermicidal effect, but current flowing from one electrode to another and through the external wire loop had a marked spermicidal action. This spermicidal action could be due to electrical currents or to the higher ionic concentrations existing as a consequence of the current flow. Studies with platinum electrodes which do not release ions showed that currents of the density available in the implantable devices have a spermicidal action (Mahajan et al., 1978), and it seems likely that the spermatozoa are being killed by the electrical current in the present device.

From the potential gradient data and interelectrode resistance data the calculated current density has an initial maximum of $0.63 \mathrm{~mA} / \mathrm{mm}^{2}$ and a stable value of $0.30 \mathrm{~mA} / \mathrm{mm}^{2}$. Past in-vitro studies (Bangham, 1961) have shown that this magnitude of current density is higher 
than the lethal threshold (Mahajan et al., 1978, 1980). During use, some polarization no doubt occurs, thereby reducing the current, but in such a case the double charge layer at the electrode surface will most probably act as a sperm-inactivating agent.

Biogalvanic cells therefore have potential as a contraceptive method. In use, reversibility may be achieved by disconnecting the electrical connections. It is also technically possible to prepare such a device so that for reversal the electrodes may be pushed out of the flow path so that the spermatozoa pass through the Teflon device only. In both these cases, the manipulations can be done through the intact scrotal wall. Since, in all circumstances the sperm pathway is open, the problem of sperm antibody production (Ansbacher, 1971; Alexander, 1972) does not arise, and the fertility rate after reversal is likely to be higher than that following vasovasostomy.

At present it is not possible to state that some spermatozoa which remain alive after passing the active device will not produce genetic defects in the offspring. The young sired by males in Group III which had $\mathrm{Al} / \mathrm{Ag}$ electrodes in situ but not shorted appeared quite normal, and it is reasonable to assume that contact with the metal electrodes themselves has no adverse effect.

\section{References}

Ahsan, R.K., Farooq, A., Kapoor, M.M. \& Laumas, K.R. (1976) Effect of intravasal copper on the fertility of male rats. J. Reprod. Fert, 48, 271-274.

Alexander, N.J. (1972) Vasectomy: long term effects in the rhesus monkey. J. Reprod. Fert. 31, 399-406.

Ansbacher, R. (1971) Sperm agglutinating and sperm immobilizing antibodies in vasectomized man. Fert. Steril. 22, 629-632.

Bangham, A.D. (1961) Electrophoretic characteristics of ram and rabbit spermatozoa. Proc. $R$. Soc. Lond. $B$ 155, 292-305.

Brueschke, E.E., Zaneveld, L.J.D., Burns, M., Rodzen, R., Wingfield, J.R. \& Maness, J.H. (1975) Development of a reversible vas deferens occlusive device. IV. Rigid prosthetic devices. Fert. Steril. 26, 29-39.
Guha, S.K., Ahmed, A.M. \& Kaur, H. (1976) Feasibility study of the reversible occlusion device for the vas deferens. Med. Biol. Eng. 13, 518-522.

Mahajan, S., Goel, M., Guha, S.K. \& Misro, M.M. (1978) Inactivation of spermatozoa by electric current. In Trends in Biomedical Engineering, pp. 251-260. Eds S. K. Guha, S. Anand \& S. Mahajan. CBME Publication, New Delhi.

Mahajan, S., Guha, S.K. \& Misro, M.M. (1980) A theoretical and SEM study of current mediated mortality of spermatozoa. J. biol. Phys. (in press).

Tarjan, P.P. (1973) Engineering aspects of implantable cardiac pacemakers. In Cardiac Pacing, pp. 47-71. Ed. P. Samet. Grune \& Stratton, Inc., New York.

Received 7 May 1981 